\title{
Uncertainty in Climate Change Projections of the Hadley Circulation: The Role of Internal Variability
}

\author{
SARAH M. KANG \\ School of Urban and Environmental Engineering, Ulsan National Institute of Science and Technology, Ulsan, South Korea \\ Clara DESER \\ Climate and Global Dynamics Division, National Center for Atmospheric Research, ${ }^{*}$ Boulder, Colorado \\ LORENZO M. POLVANI \\ Department of Applied Physics and Applied Mathematics, and Department of Earth and Environmental Sciences, \\ Columbia University, New York, New York
}

(Manuscript received 6 November 2012, in final form 17 March 2013)

\begin{abstract}
The uncertainty arising from internal climate variability in climate change projections of the Hadley circulation (HC) is presently unknown. In this paper it is quantified by analyzing a 40 -member ensemble of integrations of the Community Climate System Model, version 3 (CCSM3), under the Special Report on Emissions Scenarios (SRES) A1B scenario over the period 2000-60. An additional set of 100-yr-long timeslice integrations with the atmospheric component of the same model [Community Atmosphere Model, version 3.0 (CAM3)] is also analyzed.

Focusing on simple metrics of the $\mathrm{HC}$-its strength, width, and height - three key results emerge from the analysis of the CCSM3 ensemble. First, the projected weakening of the HC is almost entirely confined to the Northern Hemisphere, and is stronger in winter than in summer. Second, the projected widening of the HC occurs only in the winter season but in both hemispheres. Third, the projected rise of the tropical tropopause occurs in both hemispheres and in all seasons and is, by far, the most robust of the three metrics.

This paper shows further that uncertainty in future trends of the HC width is largely controlled by extratropical variability, while those of $\mathrm{HC}$ strength and height are associated primarily with tropical dynamics. Comparison of the CCSM3 and CAM3 integrations reveals that ocean-atmosphere coupling is the dominant source of uncertainty in future trends of HC strength and height and of the tropical mean meridional circulation in general. Finally, uncertainty in future trends of the hydrological cycle is largely captured by the uncertainty in future trends of the mean meridional circulation.
\end{abstract}

\section{Introduction}

The mean meridional atmospheric circulation at low latitudes is commonly referred to as the Hadley circulation (HC). It plays a central role in the earth's

\footnotetext{
* The National Center for Atmospheric Research is sponsored by the National Science Foundation.

Corresponding author address: Sarah M. Kang, School of Urban and Environmental Engineering, Ulsan National Institute of Science and Technology, 100 Banyeon-ri, Eonyang-eup, Ulsan 689798, South Korea.

E-mail: skang@unist.ac.kr
}

hydrological cycle by determining the locations of the intertropical convergence zone (ITCZ), associated with regions with the largest precipitation, as well as the large-scale subtropical dry zones, where most deserts are found. There are indications that the $\mathrm{HC}$ has been widening in recent decades (see, e.g., Seidel et al. 2008), and this would have substantial societal impacts. It is thus of great importance to accurately project changes in the $\mathrm{HC}$ in the coming decades.

To do so, it is crucial to understand the uncertainties that arise in model projections. As recently reviewed in Deser et al. (2012, hereafter DEA12), three sources of uncertainty need to be distinguished. The first is the uncertainty arising from our ignorance of the future 
forcings of the climate system. The second is the uncertainty associated with the fact that different climate models respond in different ways to identical climate forcings. The third is the uncertainty that arises from the "internal variability" of the climate system.

This last uncertainty is, in many ways, a more fundamental one, because it would persist even if the forcings were precisely known and the models were highly accurate: it is an uncertainty intrinsic to the climate system itself. The first type of uncertainty is usually estimated by carrying out projections with a number of different future scenarios. The second type is estimated by using a large number of different climate models all subject to the identical forcing scenarios. The Coupled Model Intercomparison Project (CMIP) is one such exercise (Meehl et al. 2007). The third type of uncertainty requires a large ensemble of identically forced integrations with the same model, and is only now starting to be investigated.

DEA12, one of the first studies to focus on projection uncertainties associated with internal climate variability, used a 40-member ensemble of integrations of the National Center for Atmospheric Research Community Climate System Model, version 3 (CCSM3). Each integration was forced with an identical A1B greenhouse gas (GHG) and ozone recovery scenario over the period from 2000 to 2060 . DEA12 documented the projection uncertainties associated with internal variability as reflected in three key variables: surface temperature, precipitation, and sea level pressure. In a nutshell, they found that circulation changes are considerably more uncertain than surface temperature changes, notably at mid- and high latitudes, because of the variability associated with the annular modes (Thompson and Wallace 2000).

The goal of this paper is to extend the DEA12 study and explore the uncertainties arising from internal variability, as they relate to future changes in the HC. A number of previous papers have computed future $\mathrm{HC}$ trends from phase 3 of the CMIP (CMIP3) multimodel dataset, and have reported a general weakening and widening of the HC (e.g., Lu et al. 2007, 2008; Gastineau et al. 2008). Our work differs from those, in that we here seek to document which aspects of the $\mathrm{HC}$ changes are likely to be more (or less) uncertain as a consequence of the internal variability of the climate system alone. To this end, we revisit the same 40 integrations analyzed in DEA12, but here we focus on a few simple aspects of the HC.

As recently summarized in Davis and Rosenlof (2012), part of the confusion in the recent literature regarding the discrepancies between observed and modeled trends in tropical expansion, stems from the wide variety of metrics that have been used across several different studies, some of which have been found to be unreliable (Birner 2010). For simplicity, therefore, we will here limit ourselves to three key metrics of the HC: its strength, its width, and its height.

The strength of the HC is an important metric, as it determines the intensity of the tropical hydrological cycle (for a given moisture amount), which accounts for the bulk of the global-mean precipitation and evaporation. In a warming climate, the tropical circulation is expected to weaken based on simple thermodynamic constraints (Held and Soden 2006), although the weakening occurs preferentially in the Walker cell, the zonally asymmetric component (Vecchi and Soden 2007). In fact, the CMIP3 models exhibit a very large spread in projections of $\mathrm{HC}$ weakening, with a significant $\mathrm{HC}$ trend appearing only at the $60 \%$ confidence level (Gastineau et al. 2008). How much of this uncertainty is related to internal climate variability is an open question.

The width of the HC-that is, its latitudinal extent in each hemisphere-is also an important feature of the $\mathrm{HC}$ because it controls the position of the subtropical dry zones. It also exerts a strong influence on the extratropical climate, by affecting Rossby wave propagation (Held and Phillips 1990; Esler et al. 2000). In recent decades, a poleward expansion of the $\mathrm{HC}$ has been reported in several studies, although much uncertainty remains about the amplitude of this expansion (Davis and Rosenlof 2012). Moreover, the CMIP3 models appear unable to capture the observed trends (Johanson and $\mathrm{Fu}$ 2009). How projections of tropical expansion might be affected by internal climate variability is presently unknown.

Finally, the height of the HC-characterized, for instance, by the mean tropopause height in the deep tropics-has been suggested as an important indicator of climate change (Sausen and Santer 2003). Beyond this, of course, it is well known that important flux exchanges occur (between the troposphere and the stratosphere) at the tropical tropopause, notably of water vapor and chemical constituents. In the coming decades an increase in tropopause height (i.e., a vertical expansion of the $\mathrm{HC}$ ) is expected in response to warming of the troposphere and cooling of the stratosphere (Santer et al. 2003). The robustness of this result, as it might be affected by internal climate variability, remains largely untested.

Hence, the goal of this paper is to establish which of these three metrics, each characterizing a distinct and important aspect of future changes in the $\mathrm{HC}$, is most or least uncertain, and to understand the sources of that uncertainty. For brevity the term uncertainty, here and 
elsewhere in the paper, will be used as a shortcut for "uncertainty in future trends due to internal climate variability." In the next section, we describe the model data we use and define the HC metrics precisely. In section 3, we document the uncertainty in each metric, and show that projection of the vertical HC expansion is, by far, the least uncertain. In section 4 , we analyze the relative contributions to uncertainty stemming from the sea surface temperature changes and direct atmospheric radiative forcings. More importantly, we explore the origin of uncertainty for each metric in section 5 , and show that the dominant source of uncertainty is oceanatmosphere coupling in the tropics. A brief discussion closes the paper.

\section{Models and methods}

\section{a. Models}

The primary model output used in this study is the 40-member ensemble of CCSM3 integrations described in DEA12, to which the reader is referred for more complete details. CCSM3 is a coupled ocean-atmosphereland-cryosphere general circulation model. For this 40-member ensemble, CCSM3 is run at spectral T42 horizontal truncation (corresponding, roughly, to $2.8^{\circ}$ latitude $\times 2.8^{\circ}$ longitude) for the atmosphere, land, and cryosphere components. The ocean model resolution is uniform in longitude $\left(1.125^{\circ}\right)$ and variable in latitude (from $0.27^{\circ}$ at the equator to about $0.64^{\circ}$ in the western North Pacific). The atmosphere is vertically discretized by 26 levels, 8 of which are located above $100 \mathrm{hPa}$.

Each of the 40 ensemble members is integrated for the period from 2000 to 2060, using identical external forcings: an A1B GHG scenario, stratospheric ozone recovery, and smaller changes in sulfate aerosol and black carbon, as detailed in Meehl et al. (2006). Only the atmospheric initial conditions differ from one ensemble member to the next. They are taken from different days during December 1999 and January 2000 from a single twentieth-century CCSM3 integration. Since there is no significant memory in the ocean-land-sea-ice initial conditions that last beyond about five years (Branstator and Teng 2010), they are identical for all members of the ensemble, and are taken from the conditions on 1 January 2000 from the same twentieth-century CCSM3 integration.

In addition to the above-mentioned 40-member CCSM3 ensemble, we make use of several 100-yr-long integrations of the atmospheric component of CCSM3, the Community Atmospheric Model version 3 (CAM3). These CAM3 integrations, carried out using identical horizontal and vertical resolutions as the CCSM3 integrations, are used to investigate the relative contributions of the direct effects of atmospheric radiative forcing versus the indirect effects via changes in sea surface temperature (SST) to the uncertainty in future projections. Specifically, four $100-y r-l o n g$ CAM3 integrations were performed in time-slice mode, that is, such that all forcings have no time dependence or trends other than a seasonal cycle.

The first CAM3 ensemble, labeled REF was forced using the 40-member CCSM3 ensemble-mean, monthlymean SST and sea ice concentrations (SSTs) averaged over the period $2000-09$, and with atmospheric chemical composition (mainly, GHG, and tropospheric and stratospheric ozone) also set at year 2000 levels. This is the reference integration. To examine the impact of the direct atmospheric radiative forcing on the future $\mathrm{HC}$ trend uncertainty, a second ensemble labeled ATM was analyzed. It is identical to REF, except for the atmospheric chemical composition, which was set to the 2051-60 average value. Analogously, the role of the indirect effect via SST forcing is made clear with a third ensemble, labeled SST — again, identical to REF, except for the prescribed SSTs, which were set to the 2051-60 mean. A final ensemble, labeled SST+ATM, was forced with both SSTs and atmospheric chemical composition at 2051-60 mean levels. This labeling scheme is identical to the one used in Deser and Phillips (2009), where similar forcing combinations were used. The characteristics of internal variability in CCSM3 and CAM3 have been extensively documented in a special issue of the Journal of Climate (2006, Vol. 19, No. 11) devoted to CCSM3. In general, CCSM3 realistically simulates the major patterns of internal climate variability, although the ENSO period is shorter than observed (Deser et al. 2006).

\section{b. Methods}

As already mentioned, we focus our study on three key metrics that describe the $\mathrm{HC}$ in simple terms: the strength, the width, and the height. The first two are quantified from the mean meridional streamfunction $\Psi$, defined by

$$
\Psi(\phi, p)=\frac{2 \pi a \cos \phi}{g} \int_{p}^{0} \bar{v}\left(\phi, p^{\prime}\right) d p^{\prime},
$$

where $\phi$ is latitude, $p$ is pressure, $\bar{v}$ is the zonally averaged meridional wind, $a$ is the radius of the earth, and $g$ is the gravitational acceleration.

The strength $\Psi_{\max }$ of the HC is defined as the maximum value of $\Psi$ at $500 \mathrm{hPa}$, in each hemisphere. The width $\phi_{\Psi=0}$ of the $\mathrm{HC}$ is defined as the latitude of its 
poleward edge, in each hemisphere. More precisely: $\phi_{\Psi=0}$ is here computed as the latitude where $|\Psi|$ falls to $10 \%$ of $\Psi_{\max }$ at $500 \mathrm{hPa}$. We use the $10 \%$ threshold, instead of the zero crossing, because the summer $\mathrm{HC}$ is so weak (especially in the Northern Hemisphere) that in some models and years the zero crossing of $\Psi$ at $500 \mathrm{hPa}$ is ill defined. The height $P_{t}$ is defined as the averaged tropopause pressure, centered at the latitude of $\Psi_{\max }$ with a latitudinal width of $10^{\circ}$, in each hemisphere; the tropopause is computed following the algorithm of Reichler et al. (2003), which uses the thermal definition of the tropopause.

To compute the climate response, we calculate the epoch differences between the last $10 \mathrm{yr}$ (2051-60) and the first $10 \mathrm{yr}$ (2005-14) of each model integration. As shown in DEA12, using the epoch difference yields similar results to computing linear trends. We will therefore refer to the epoch differences as the "trends" in the text below. For the CAM3 integrations, to enable direct comparison to CCSM3, we first construct 40 sets of 10 arbitrarily chosen years from the 100-yr CAM3 time-slice integrations, thereby building 40 ensemble members. Then, the response is the $10-\mathrm{yr}$ mean difference between the REF integration and any of the forced integrations.

To evaluate the uncertainty of the climate response we compute $N_{\min }$, the minimum number of ensemble members needed to detect the response with $95 \%$ statistical confidence. Again, following DEA12, we define $N_{\min }$ as

$$
N_{\min }=8 /(X / \sigma)^{2},
$$

where $X$ is the ensemble-mean trend of a given quantity (e.g., the tropopause height), and $\sigma$ is the standard deviation, computed from the 40 individual trends, of the same quantity. It should be clear that large values of $N_{\min }$ reflect high uncertainty for a given quantity, and vice versa.

Finally, as in DEA12, we characterize the dominant patterns in the uncertainty of the climate response by conducting an EOF analysis on the set of 40 trend maps. First, the uncertain component of mean meridional circulation trend for each ensemble member is computed by removing the ensemble mean of $\Psi$ trends from the $\Psi$ trend of that ensemble member: this quantity is denoted as $\Delta \Psi^{\prime}$. Then, the singular vector decomposition (SVD) is performed on $\Delta \Psi^{\prime}$ - that is, $\Delta \Psi^{\prime}=\mathbf{U S V}^{\mathrm{T}}$-where the columns of $\mathbf{U}$ are the EOFs. We note that for zonally averaged quantities (e.g., zonal-mean precipitation minus evaporation in Fig. 8), the square root of $\cos \phi$ is multiplied before applying the SVD to account for the area-weighted covariance matrix. To distinguish the dominant patterns in the extratropics and in the tropics, a separate EOF analysis is computed for each hemisphere poleward of $30^{\circ}$ and for the tropics $\left(30^{\circ} \mathrm{S}-30^{\circ} \mathrm{N}\right)$. The leading principal component (PC1) is obtained as the first column of $a=\mathbf{V S}^{\mathrm{T}}$; and the variance explained by the leading mode is obtained as $L=S(1,1)^{2} / N$, where $N$ is the size of an ensemble $(=40)$. To illustrate the entire global pattern of $\Psi$ trend uncertainty, we plot regressions of $\Delta \Psi^{\prime}$ onto the standardized PC record $\left(a^{\prime}=a / \sqrt{L}\right)$ : this quantity will be referred to as "the leading EOF of $\Psi$ trend uncertainty" (and is shown in Fig. 7, to be discussed below). Similarly, regressions of precipitation minus evaporation $(P-E)$ trends onto $a^{\prime}$ will be discussed (in conjunction with Fig. 8) in section 5 .

\section{Uncertainties in future Hadley cell trends}

We start by considering the ensemble-mean trends of the zonal-mean meridional stream function $\Psi$, shown by the colors in Figs. 1a and 1b, for December-February (DJF) and June-August (JJA) (left and right, respectively). In those panels we also plot its ensemble-mean climatology (2005-14), shown by the black contours. To guide the eye, we draw an $\times$ symbol at the latitude of the climatological $\Psi_{\max }$ in each hemisphere (which we denote as $\phi_{\max }$ ); we also mark the poleward edges of the climatological cells in each hemisphere with a + symbol; and, finally, we draw a horizontal line segment where the model's climatological, zonal mean, thermal tropopause averaged over the latitudes with a center at $\phi_{\max }$ and a width of $10^{\circ}$ is found in each season.

Several points can be gathered from Figs. 1a and $1 b$. First, as the winter cells are climatologically stronger than the summer cells, the trends are found to be stronger in the winter hemispheres: this hemispheric asymmetry is particularly clear for DJF. Also, in that season, we see a clear HC weakening of the winter cell (see how the dark blue region overlaps much of the winter cell and the $\times$ of northern $\phi_{\max }$ ). In JJA, in contrast, the $\Psi$ trends happen to change sign just around the southern $\phi_{\max }$, indicating a $\mathrm{HC}$ weakening in the northern tropics but a strengthening in the southern tropics. Similarly, in the summer hemispheres, the edges of the climatological cells $(+)$ fall in latitudes with no $\Psi$ trends, suggesting that only the winter hemisphere will show statistically significant expansion. The bottom line is that $\Psi$ trends show a surprisingly complex structure, suggesting that widely used metrics (such as $\Psi_{\max }$ and $\phi_{\Psi=0}$ ) may not be adequate to capture changes in the HC.

This conclusion is reinforced in Figs. 1c and 1d, where we show $N_{\text {min }}$, the minimum size of an ensemble needed to establish a statistically significant $\Psi$ trend, as defined 
(a) DJF trend/clim

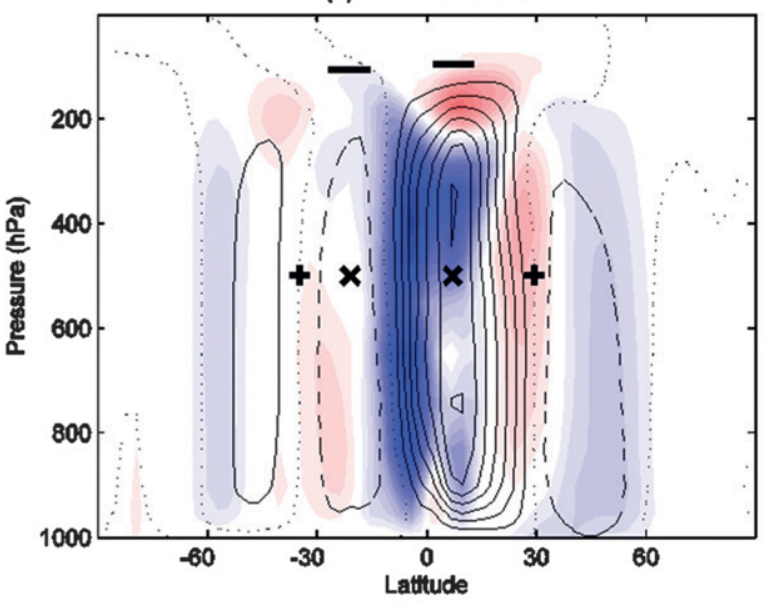

(b) DJF $\mathbf{N}_{\min }$

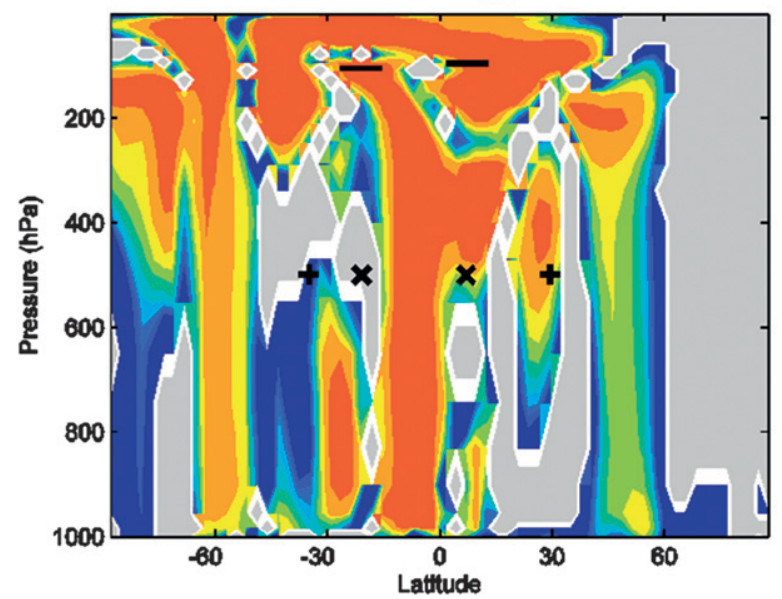

(c) JJA trend/clim

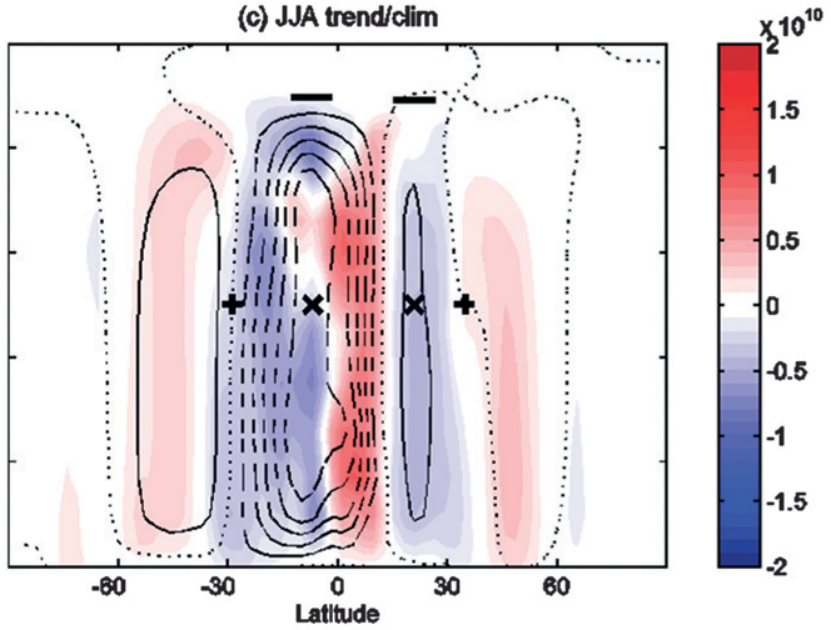

(d) JJA N

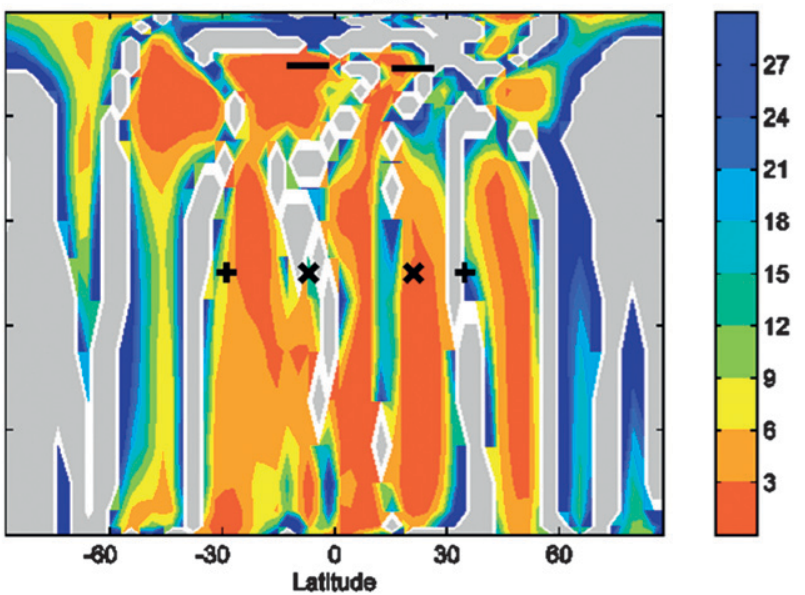

FIG. 1. (a),(c) CCSM3 40-member ensemble-mean $\Psi$ climatology (black contours) and trends (colors). Positive values (red shading and solid contours) indicate clockwise circulation; negative values (blue shading and dashed contours) counterclockwise circulation. Black contour interval: $5 \times 10^{10} \mathrm{~kg} \mathrm{~s}^{-1}$. (b),(d) The $N_{\text {min }}$, needed to detect significant trends. Gray areas indicate locations where trends are not significant at the $95 \%$ confidence level. In all panels, the climatological latitudes $\phi_{\max }$ are marked with an $\times, \phi_{\Psi=0}$ with a + , and $P_{t}$ with a horizontal line segment in each hemisphere; (left) DJF and (right) JJA.

in Eq. (2). These panels can be contrasted directly with the corresponding plots for surface temperature, precipitation, and sea level pressure (SLP) shown in the left column of Fig. 1 in DEA12. Note the highly complex latitudinal structure of $N_{\min }$ for $\Psi$ trends, in contrast to the much simpler structure for $N_{\min }$ of surface temperature in DEA12. This confirms and extends a result already reported in DEA12, namely, that circulation trends in some locations can be more uncertain than surface temperature changes. Furthermore, the $\times$ and + symbols fall, in many cases, where no statistically significant trends are found, or where a large number of model integrations is required to establish trends, again suggesting the lack of robustness of many HC trends.
To bring out the relative uncertainty of the individual $\mathrm{HC}$ metrics, we plot in the top row of Fig. 2 the computed trends for each of the three metrics (the individual ensemble members with crosses, the ensemble mean with a bar); in the bottom row, the corresponding $N_{\text {min }}$ values are shown. For each panel, both the DJF (left) and JJA (right) results are given, and the light and dark bars show the Southern and Northern Hemispheres ( $\mathrm{SH}$ and $\mathrm{NH}$ ), respectively.

Consider first the HC strength as quantified by $\Psi_{\max }$, shown in Figs. 2a and 2b. Robust weakening trends are clear in the NH (dark gray bars), in both seasons, with only a handful of ensemble members needed to establish a statistically significant result $\left(N_{\min } \leq 4\right)$. The $\mathrm{SH}$ in 

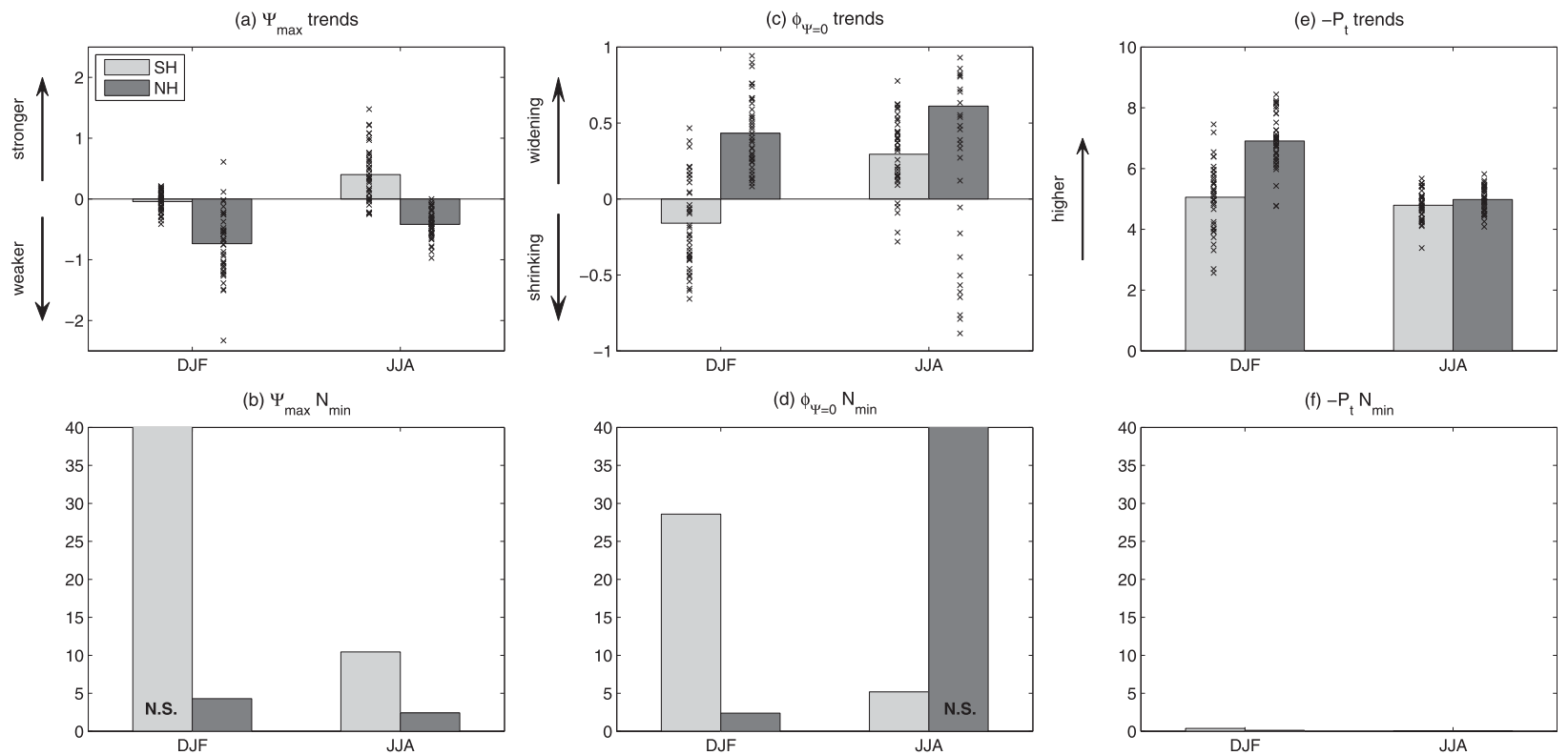

FIG. 2. (a) Trends of HC strength $\left(\Psi_{\max }\right.$ in $\left.10^{10} \mathrm{~kg} \mathrm{~s}^{-1}\right)$ and (b) corresponding $N_{\text {min }}$, from 40-member CCSM3 ensemble. (c),(d) As in (a),(b), but for the HC edge $\left(\phi_{\Psi=0}\right.$ in $\left.^{\circ}\right)$. (e),(f) As in (a),(b), but for the HC height $\left(-P_{t}\right.$ in hPa). Light (dark) gray shows the SH (NH). (top) Bars denote ensemble-mean trends, and $\times$ symbols denote individual ensemble member trends. (bottom) The initials N.S. indicate that the ensemble-mean response is not significant at the $95 \%$ confidence level.

contrast, shows highly uncertain trends in HC strength, actually insignificant in DJF. A slight strengthening in JJA is misleading, as noted above in reference to Fig. 1b, since $\Psi$ trends in that season show a dipole pattern, with strengthening and weakening to the south and north of the center of the southern cell. The lesson here is that although the $\mathrm{HC}$ has been reported to weaken with global warming (e.g., Lu et al. 2007), one needs to qualify that statement, insofar as the weakening appears to be robust only in the $\mathrm{NH}$, at least in CCSM3.

As for the width of the HC, Figs. $2 \mathrm{c}$ and $2 \mathrm{~d}$ show that it is not the hemisphere that matters but the season. In summer, the $\mathrm{HC}$ width trends are highly uncertain: in the $\mathrm{SH}$ this is due to the cancellation between ozone recovery and increasing GHG (Polvani et al. 2011), and in the NH the huge uncertainty arises from the fact that the $\mathrm{HC}$ is exceedingly weak (see Fig. 1b) and hence the edge is barely detectable. In contrast, the winter $\mathrm{HC}$ widens robustly in both hemispheres, with only a few ensemble members needed to establish the result $\left(N_{\min } \leq 3\right)$. This seasonality in the detectability of HC widening has been discussed in Kang and $\mathrm{Lu}$ (2012). Again, therefore, the widening statement needs to be qualified, as the HC expansion appears to occur robustly only in the winter season.

Finally, the trends for the $\mathrm{HC}$ height are shown in Figs. 2e and $2 \mathrm{f}$. These trends are remarkably robust, with a single model integration sufficient to detect the trends, irrespective of season and hemisphere (in fact, $N_{\min } \sim$ 0.1 ). This result is particularly surprising, in that our model is not a stratosphere-resolving model, and thus the resolution around the tropical tropopause is relatively coarse. The robustness of the future vertical expansion of the tropical mean meridional circulation suggests that this metric might be as reliable as surface temperature as a possible fingerprint of global warming, as suggested in Sausen and Santer (2003).

\section{Relative contributions of SST forcing and direct atmospheric radiative forcing}

We now turn to analyzing the CAM3 integrations with single forcings, that is, the atmospheric model integrations with SSTs and atmospheric constituents altered independently. The 40-member ensemble-mean $\Psi$ trends for these integrations are shown in Fig. 3, with DJF in the left column and JJA in the right one. The top row shows the trends for the SST + ATM case, the middle row for SST, and the bottom row for ATM. The trends are shown in color, and the black contour shows the "climatology" (i.e., the 40-member mean of the REF integration).

The first thing to note, comparing Figs. 3a and 3d with Figs. 1a and 1c, is the close similarity between the CAM3 SST+ATM trends and the CCSM3 trends. This confirms that the atmospheric model alone is able to 
(a) DJF SST+ATM

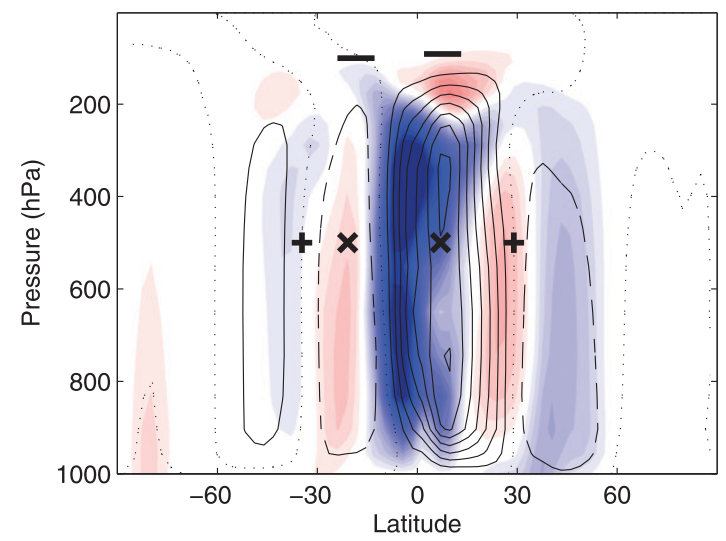

(b) DJF SST

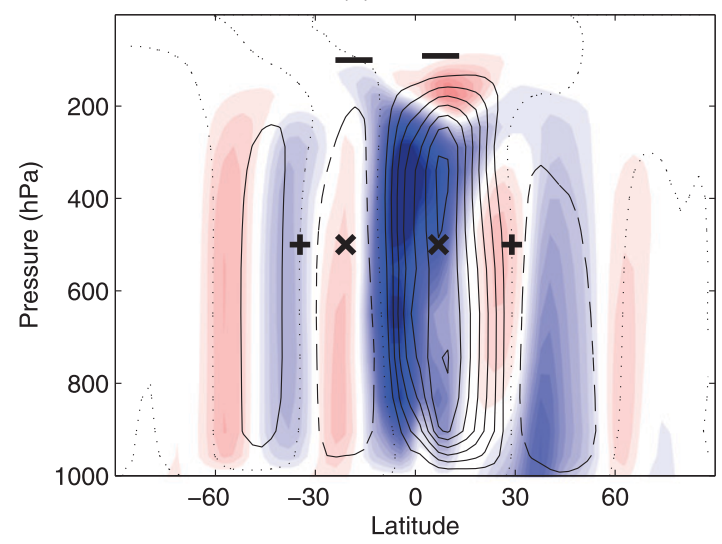

(c) DJF ATM

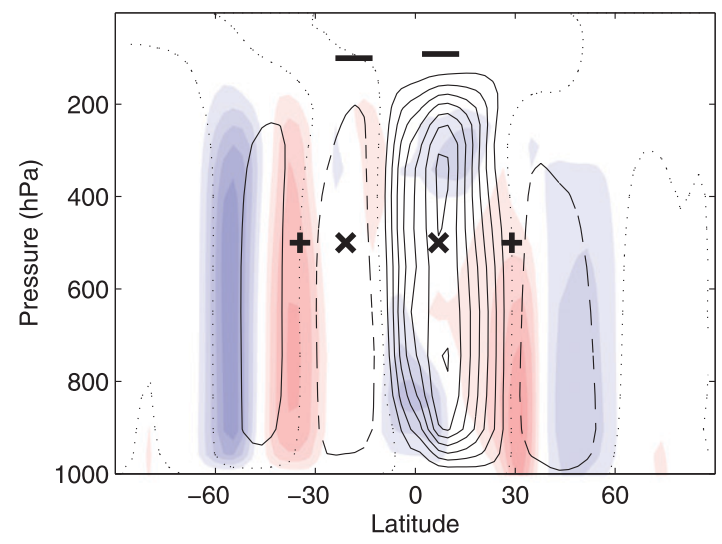

(d) JJA SST+ATM

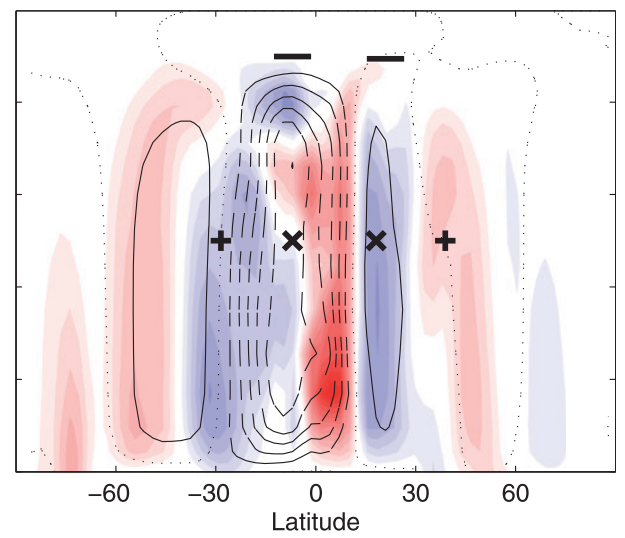

(e) JJA SST

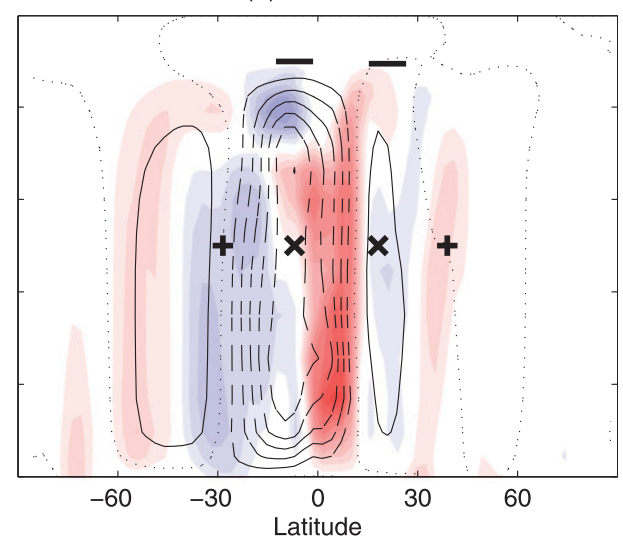

(f) JJA ATM

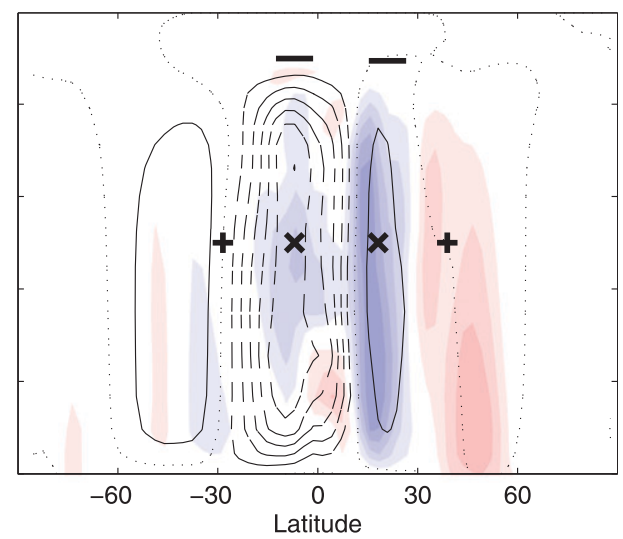

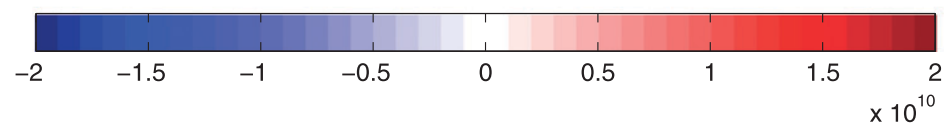

FIG. 3. As in Figs. 1a and 1c, but for the CAM3 integrations: (a),(d): SST+ATM, (b),(e) SST, and (c),(f) ATM. Black contours show the ensemble mean for the unforced REF case. 

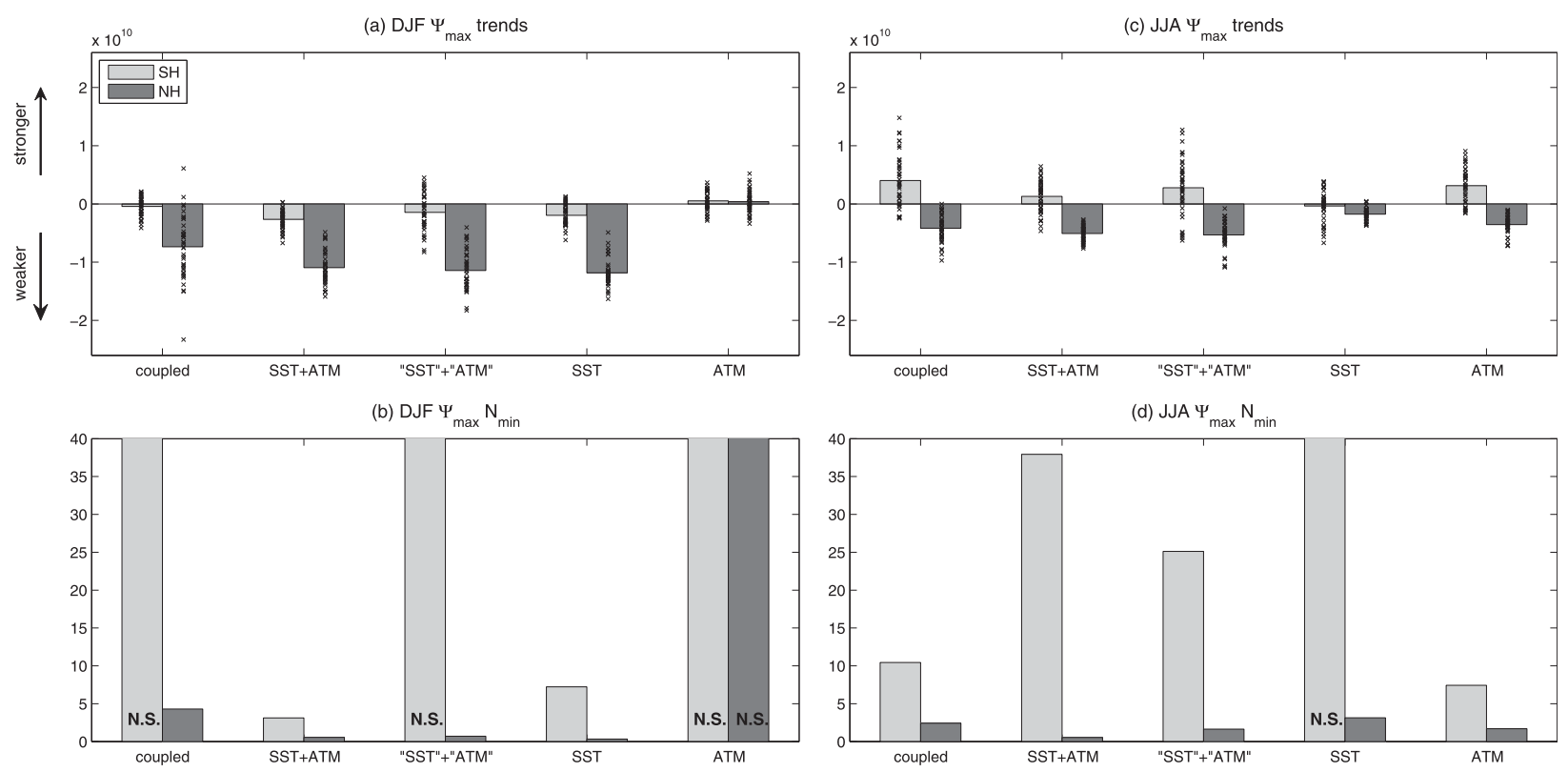

FIG. 4. CCSM3, CAM3 SST+ATM, the sum of CAM3 SST and CAM3 ATM, CAM3 SST, and CAM3 ATM for (a),(c) trends in HC strength and (b),(d) corresponding $N_{\min }$, for (left) DJF and (right) JJA.

accurately reproduce the trends of the coupled model once the SSTs and atmospheric constituents are specified (Deser and Phillips 2009). The uncertainties, however, are not always the same between the two but are dependent on the HC metrics, as discussed below. Second, contrasting the top and middle rows in Fig. 3, one can see that the tropical $\Psi$ trends result primarily from changes in SSTs in both seasons. Third, note the nearly equal and opposite DJF trends in the latitude band $30^{\circ}-$ $60^{\circ} \mathrm{S}$ (Figs. $3 \mathrm{~b}$ and $3 \mathrm{c}$ ), showing the nearly total cancellation between increasing GHG (SST case) and ozone recovery (ATM case), already documented in Polvani et al. (2011).

We now consider, one by one, the three HC metrics, and how they are affected by the different forcings, starting with the HC strength. Figure 4 summarizes, for $\Psi_{\max }$, the trends and $N_{\min }$ values. The NH trends are quite robust, showing a clear weakening response, as we have already noted, irrespective of season and forcing. The cause for this weakening, however, appears to depend on the season. The left panels in Fig. 4 clearly suggest that the SSTs are responsible for the $\mathrm{NH}$ weakening in DJF; the right panels, in contrast, indicate that SSTs are not the immediate cause for the $\mathrm{NH}$ weakening in JJA. Whether this behavior is peculiar to CAM3 we cannot tell at this point, and rather than speculate we await confirmation of this result with a different model before attempting an explanation. In contrast, the $\mathrm{SH}$ trends exhibit high uncertainty, which stems from direct atmospheric radiative forcing in DJF and from SST forcing in JJA.
Turning next to the widening of the $\mathrm{HC}$, the trends and $N_{\min }$ for $\phi_{\Psi=0}$ are shown in Fig. 5. The key result for the coupled CCSM3 integrations - that is, that widening is robust only in the winter hemisphere-is also seen in the CAM3 integrations (contrast the two leftmost pairs of bars in each panel, showing the coupled and uncoupled SST + ATM results, respectively). However, in the uncoupled integrations, the widening trend in the $\mathrm{NH}$ also appears to be robust in summer (Fig. 5d). The widening of the winter hemisphere $\mathrm{HC}$ results from the indirect effect of the atmospheric radiative forcing (e.g., via SST changes). The same conclusion can be drawn from Fig. 6 in the case of the HC height metric. Note the very low values of $N_{\min }$ for all ensembles of integrations, except for the ATM one. The SSTs, therefore, appear to be the key players in nearly all robust trends associated with the tropical mean meridional circulation.

\section{Characterization of uncertainties in future trends}

We now characterize the dominant patterns of uncertainty in future trends, along the lines of DEA12, with an EOF analysis as described at the end of section 2. The top, middle, and bottom rows of Fig. 7 show the global distribution of $\Psi$ trend uncertainty $\left(\Delta \Psi^{\prime}\right)$ regressed upon the leading PC of tropical, southern extratropical, and northern extratropical $\Delta \Psi^{\prime}$, respectively, for both DJF (left column) and JJA (right column).

In both seasons, the leading tropical EOF (EOF1; Figs. $7 \mathrm{a}$ and $7 \mathrm{~d}$ ) is characterized by a modulation of $\mathrm{HC}$ 

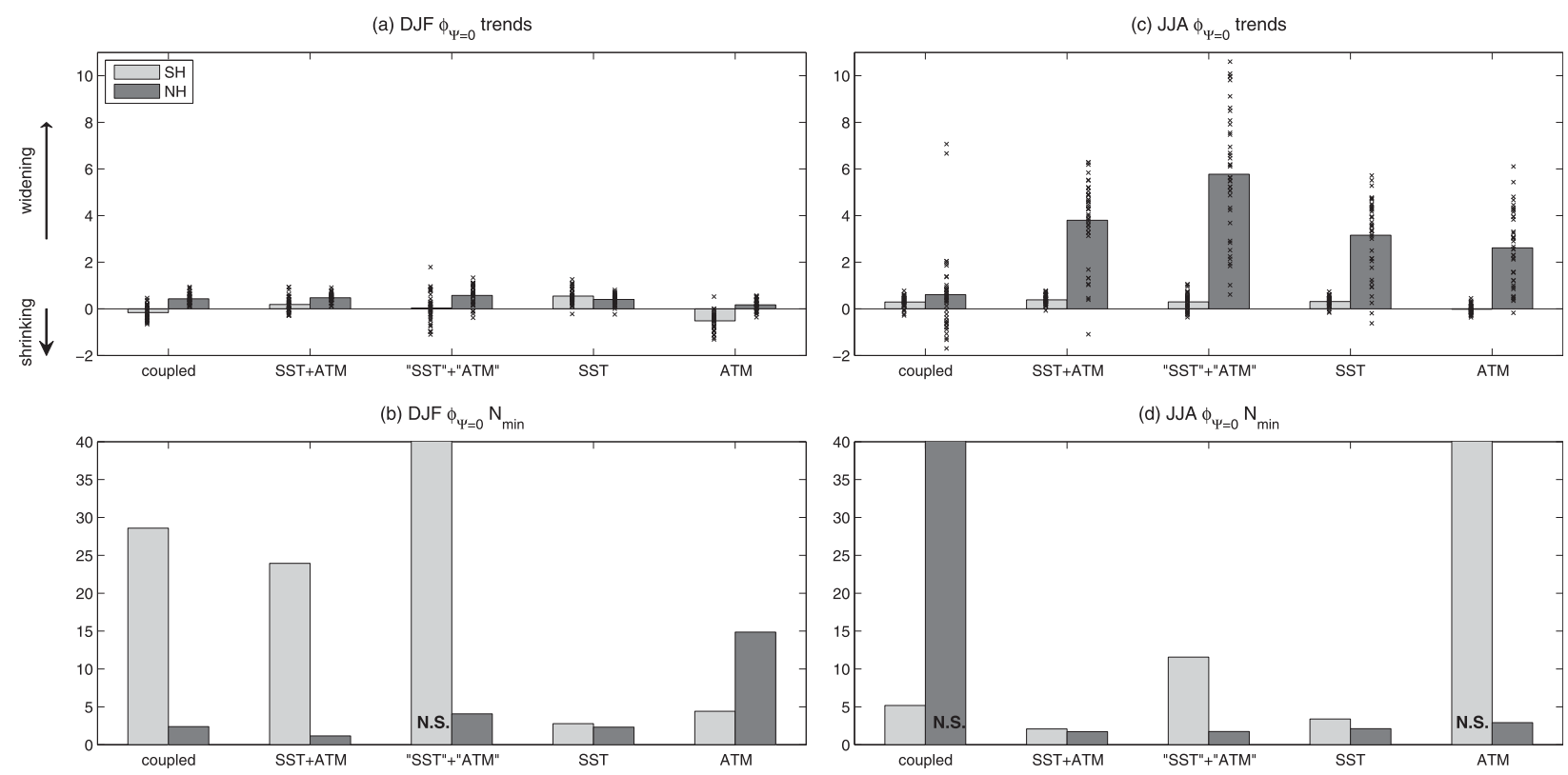

FIG. 5. As in Fig. 4, but for the HC edge $\left(\phi_{\Psi=0}\right.$ in $\left.{ }^{\circ}\right)$.

strength centered around the equator. It explains $47 \%$ of the variance in tropical $\Psi$ trends in both seasons. Note that, although the EOF analysis is restricted to the tropics, nonnegligible regression coefficient amplitudes are found in the extratropics. The leading extratropical EOF (middle and bottom panels) is characterized by the Ferrel cell (FC) shift, associated with an annular mode structure in both seasons and hemispheres. It is interesting to note that in DJF, the extratropical EOF1 of one hemisphere is linked to the other hemisphere: a poleward shift of the southern FC accompanies a poleward shift of the northern FC and vice versa. However, these hemispheric modes occur independently of one another, as indicated by the near-zero correlation between the PC records in the $\mathrm{NH}$ and $\mathrm{SH}$ (in both CCSM3 and CAM3 ensembles); a similar result for the PCs of the sea level pressure was reported in DEA12. The extratropical EOF1 in general explains a larger fraction (a) DJF - P trends

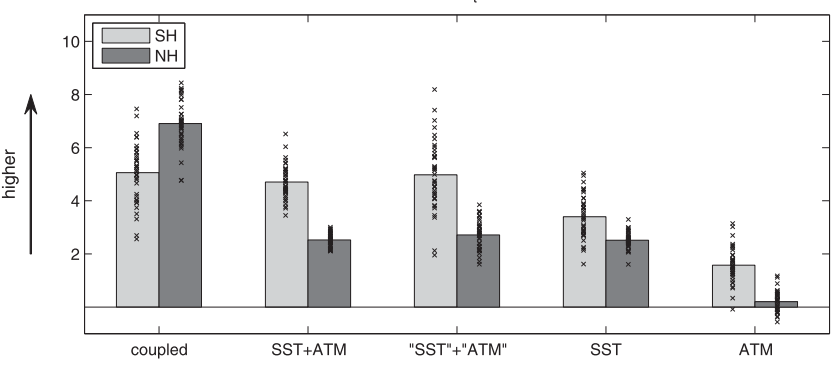

(b) DJF $-P_{t} N_{\text {min }}$

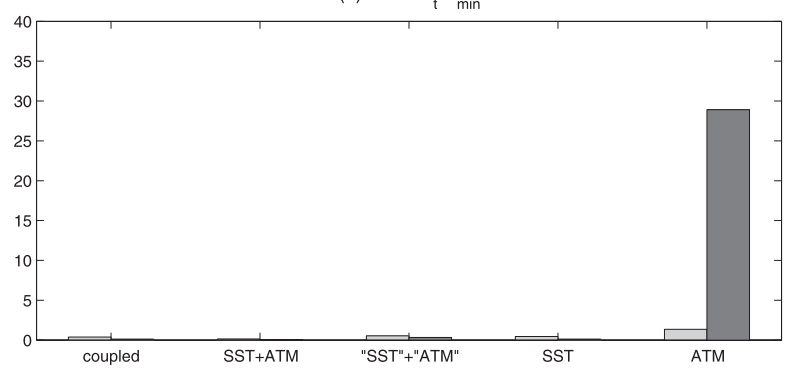

(c) JJA $-P_{\text {t }}$ trends

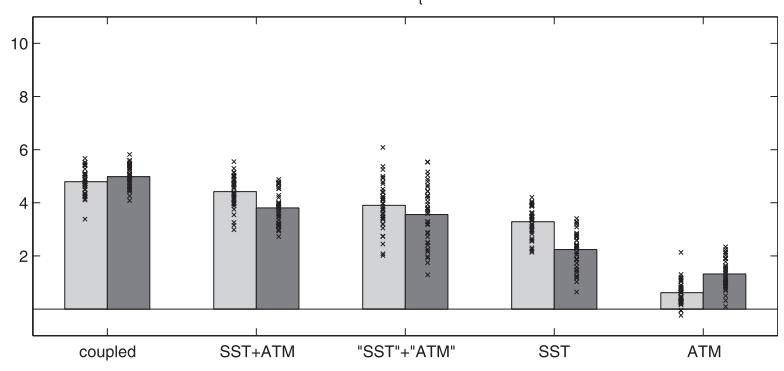

(d) JJA $-\mathrm{P}_{t} \mathrm{~N}_{\min }$

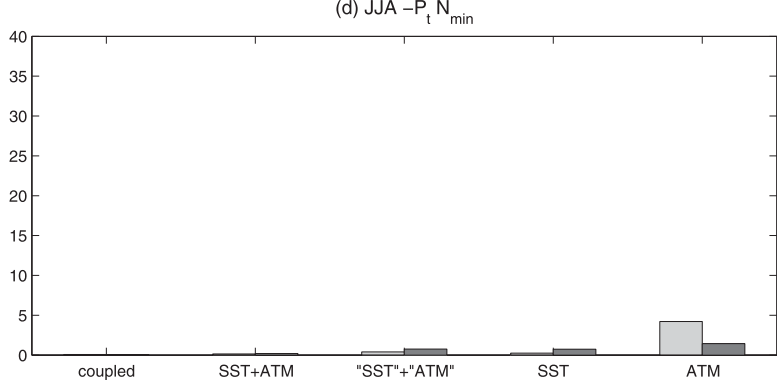

FIG. 6. As in Fig. 4, but for the HC height $\left(-P_{t}\right.$ in hPa). 
(a) DJF Trop EOF1 (46)

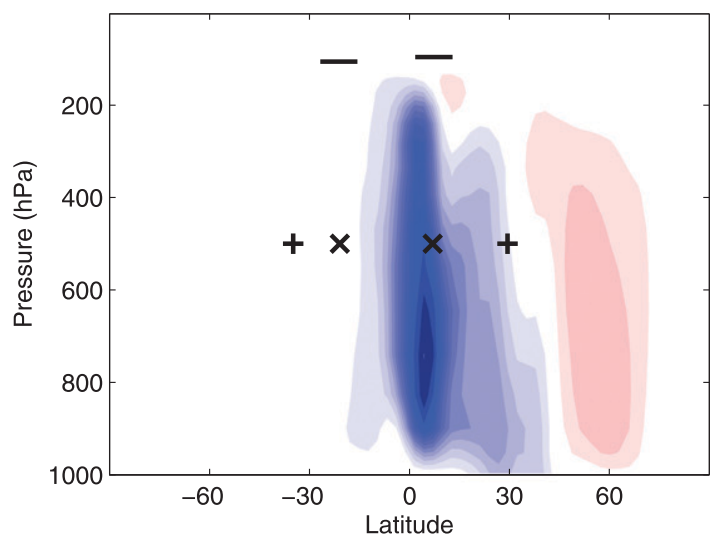

(b) DJF SH ExT EOF1 (59)

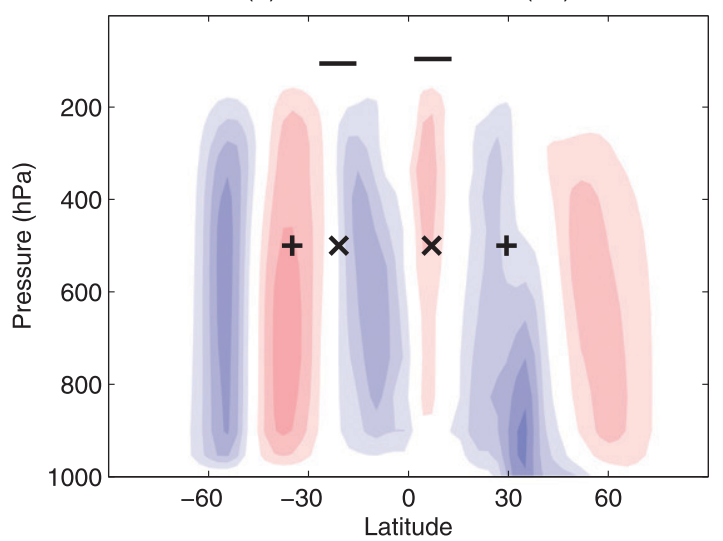

(c) DJF NH ExT EOF1 (55)

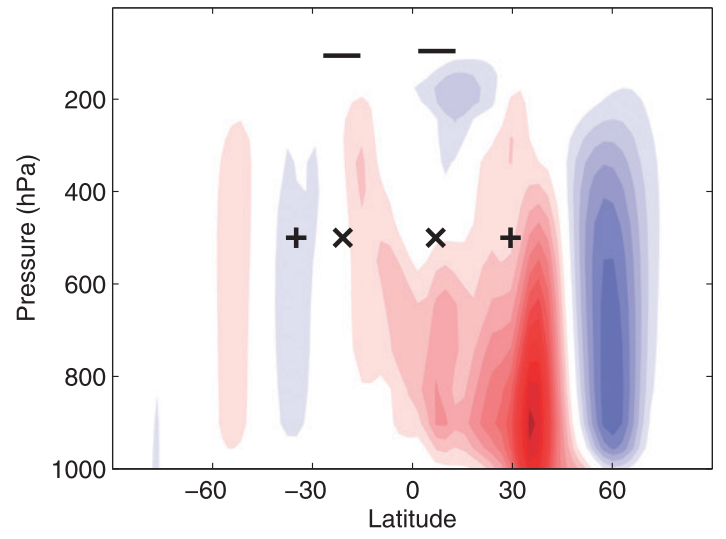

(d) JJA Trop EOF1 (47)

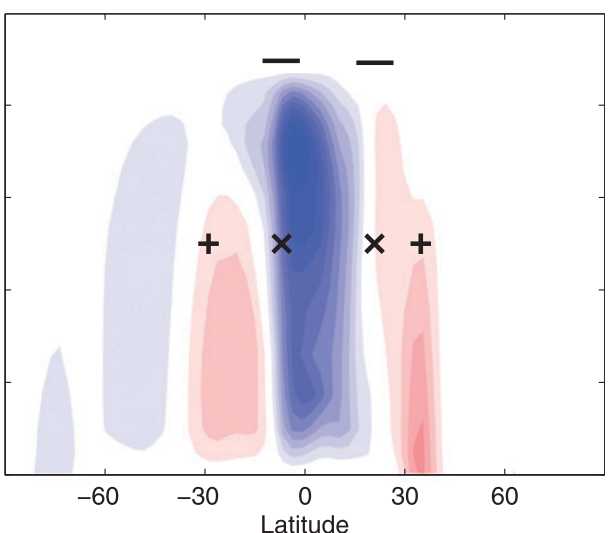

(e) JJA SH ExT EOF1 (44)

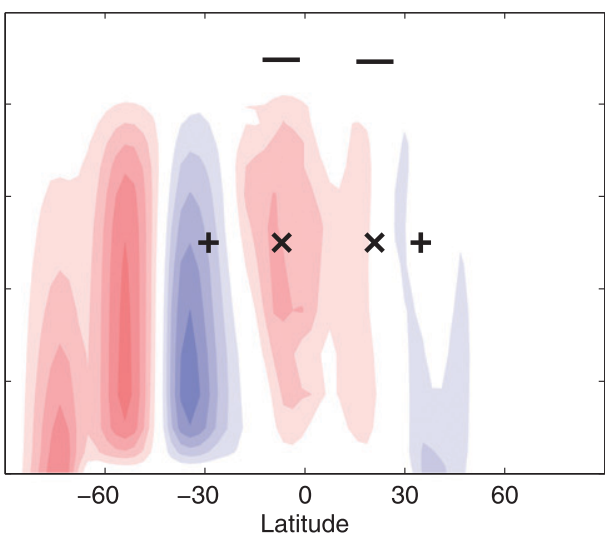

(f) JJA NH ExT EOF1 (48)

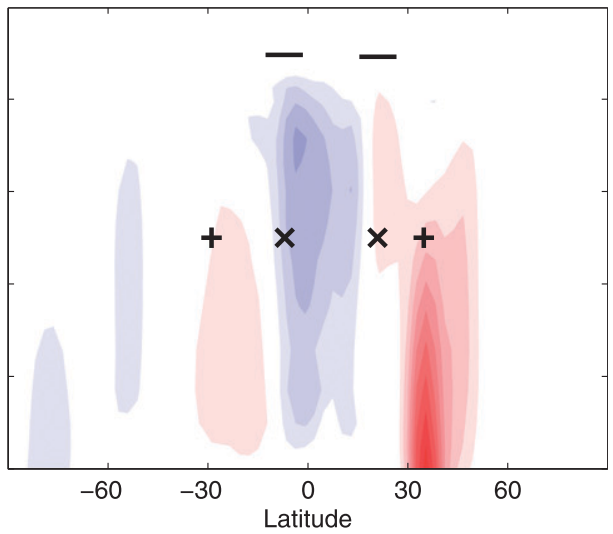

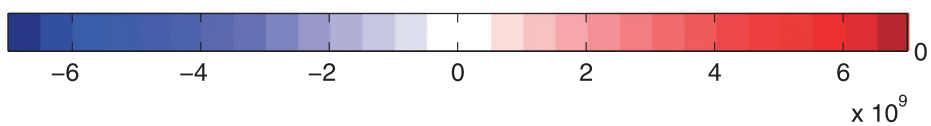

FIG. 7. Global distribution of $\Psi$ trend uncertainty $\left(\Delta \Psi^{\prime}\right)$ regressed upon PC1 of $\Delta \Psi^{\prime}\left(\mathrm{J} \mathrm{kg}^{-1}\right)$ in the (a), (d) tropics $\left(30^{\circ} \mathrm{S}-30^{\circ} \mathrm{N}\right),(\mathrm{b}),(\mathrm{e})$ southern extratropics $\left(90^{\circ}-30^{\circ} \mathrm{S}\right)$, and (c), (f) northern extratropics $\left(30^{\circ}-90^{\circ} \mathrm{N}\right)$, from CCSM3 40 -member ensemble, for (left) DJF and (right) JJA. Percent variance explained by each EOF is given in the topright corner of each panel. 
TABLE 1. Pattern correlation between the EOF1 of uncertainty in $\Psi$ trends from 40-member CCSM3 and CAM3 SST+ATM Values in the parentheses are the correlation coefficients within the latitudinal bands where the EOF is computed $\left[30^{\circ} \mathrm{S}-30^{\circ} \mathrm{N}\right.$ for tropics (trop) and $30^{\circ}-90^{\circ} \mathrm{S} / \mathrm{N}$ for extratropics (ExT)].

\begin{tabular}{lccc}
\hline & Trop & SH ExT & NH ExT \\
\hline DJF & $0.25(0.29)$ & $0.64(0.99)$ & $0.87(0.97)$ \\
JJA & $0.39(0.51)$ & $0.84(0.97)$ & $0.72(0.94)$ \\
\hline
\end{tabular}

of the variance than the tropical EOF1, and the largest variance $(59 \%)$ is explained by the southern extratropical EOF1 in DJF.

For clarity, we only show in Fig. 7 results for the CCSM3 ensemble: the extent to which the leading EOF of $\Psi$ trend uncertainty in CAM3 resembles that in CCSM3 is quantified by computing the correlation coefficients between the two models (Table 1). The first number indicates the pattern correlation coefficient using the global map in Fig. 7, and the number in the parenthesis indicates the correlation coefficient within the latitudinal bands where the EOF is computed $\left(30^{\circ} \mathrm{S}-30^{\circ} \mathrm{N}\right.$ for tropical EOF and $30-90^{\circ} \mathrm{S}-\mathrm{N}$ for southern and northern extratropical EOFs) and hence the greater values in the parenthesis. For the extratropical EOF1, a strong correlation between the CCSM3 and CAM3 exists: it reaches up to 0.87 in NH DJF when the global pattern is used and is nearly 1 (for both seasons and hemispheres) when the specified latitudinal band is used. This implies the extratropical pattern, which largely characterizes variability associated with the annular modes, is a result of internal atmospheric variability alone. However, the tropical EOF1 exhibits a much weaker correlation between the coupled and uncoupled models, indicating that coupled ocean-atmosphere variability is important in the tropics.

The question is then how the dominant patterns of $\Psi$ trend uncertainty in Fig. 7 are related to the trend uncertainty of each of the simple $\mathrm{HC}$ metrics shown in Fig. 2. In Table 2, we show the correlation coefficient between the leading PC records of $\Psi$ trend uncertainty and the trend of each HC metric $\left(\Psi_{\max }, \phi_{\Psi=0}\right.$, and $\left.-P_{t}\right)$, for the CCSM3 ensemble. The first number denotes the DJF value and the second number JJA. Values significant at $1 \%$ according to the two-tailed Student's $t$ test and sufficiently large $(>0.5)$ are displayed in bold. As shown in Table 2, the tropical $\Psi$ EOF1 is well correlated with the $\mathrm{HC}$ strength in the winter hemisphere, whereas the extratropical EOF1 is well correlated with the HC edge in the summer hemisphere. This is consistent with the understanding that the weak summer $\mathrm{HC}$ is subject to the influence of eddy momentum fluxes originating from the midlatitudes, whereas the strong winter $\mathrm{HC}$ is more constrained by the angular momentum conservation and is shielded from extratropical eddies
TABLE 2. Correlation coefficient between PC1 of uncertainty in $\Psi$ trend and the uncertainty in the trend of the maximum $\mathrm{HC}$ strength in the $\mathrm{SH}$ (first row) and the $\mathrm{NH}$ (second row), the HC edge in the $\mathrm{SH}$ (third row) and the $\mathrm{NH}$ (fourth row), and the $\mathrm{HC}$ height in the $\mathrm{SH}$ (fifth row) and the NH (sixth row). First value is for DJF and the second value is for JJA. Results based on CCSM3. Values significant at $1 \%$ according to the two-tailed Student's t test and larger than 0.5 are displayed in bold.

\begin{tabular}{lrcr}
\hline & Trop PC1 & SH ExT PC1 & NH ExT PC1 \\
\hline SH $\Psi_{\max }$ & $-0.05 / \mathbf{0 . 7 1}$ & $0.33 /-0.33$ & $-0.14 / 0.31$ \\
NH $\Psi_{\max }$ & $-\mathbf{0 . 9 1} / 0.25$ & $0.19 / 0.08$ & $0.09 / 0.30$ \\
SH $\phi_{\Psi 500}$ & $0.01 / \mathbf{0 . 5 7}$ & $\mathbf{0 . 9 1} /-\mathbf{0 . 5 9}$ & $-0.36 / 0.33$ \\
NH $\phi_{\Psi 500}$ & $-0.20 / 0.49$ & $-0.47 /-0.27$ & $0.35 / \mathbf{0 . 5 8}$ \\
SH $-P_{t}$ & $-0.01 / 0.34$ & $\mathbf{0 . 6 8} /-0.16$ & $-0.24 / 0.19$ \\
NH $-P_{t}$ & $-0.05 / 0.47$ & $\mathbf{0 . 5 5} /-0.22$ & $-0.34 / 0.24$ \\
\hline
\end{tabular}

(Schneider and Bordoni 2008; Bordoni and Schneider 2010). Moreover, Table 2 indicates that the northern extratropical $\Psi$ EOF1 in JJA is less correlated with the $\mathrm{NH} \mathrm{HC}$ edge (0.58) compared to its $\mathrm{SH}$ counterpart in DJF (0.91). This may be because the NH HC edge is not well defined because of the very weak northern summer $\mathrm{HC}$ and large zonal asymmetries in the $\mathrm{NH}$, as noted in Kang and Polvani (2011). Thus, the HC strength is more associated with tropical dynamics, and the $\mathrm{HC}$ edge is more controlled by extratropical dynamics. It is, however, noted that the correlation between the HC edges with the tropical $\Psi$ EOF1 in JJA is also fairly large in both hemispheres, so that it is feasible that tropical sources of uncertainty can also influence the extent of the HC. In contrast to HC strength and width, uncertainties in $\mathrm{HC}$ height trends are not consistently related to any of the leading patterns of uncertainty in $\Delta \Psi^{\prime}$, except for the southern extratropics (Table 2). Thus, there appears to be a decoupling in the trend uncertainties between the thermally based $\mathrm{HC}$ height metric and the dynamically based $\Psi$ EOF1 patterns.

Last, we take a look at the hydrological cycle by considering how the leading pattern of $\Psi$ trend uncertainty is associated with the trend uncertainty in the zonalmean hydrological cycle $(P-E)$ in CCSM3 (Fig. 8). In both seasons, the leading $P-E$ trend EOF (dashed) is very similar to the $P-E$ trend regression patterns associated with $\Psi$ trend EOF1 (solid), with a pattern correlation (within the specified latitudinal band used for EOF analysis) ranging from 0.90 to 0.99 , except for the NH JJA, which exhibits a lower pattern correlation of 0.35 due to differences at high latitudes. Similarly, high values are found when the pattern correlations are not restricted to the specified latitudinal band but computed globally, as evidenced by the similarity of the solid and dashed curves in Fig. 8. The only exception to this is for the northern extratropical $\Psi$ EOF1 in DJF, which shows large differences in $P-E$ values in the 
(a) Trop (20/17)
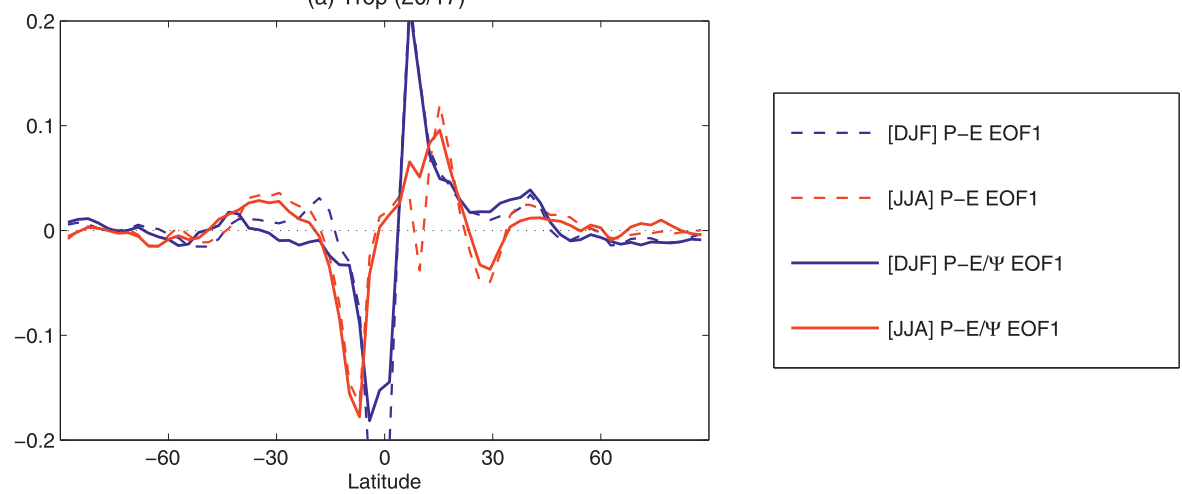

(b) SH ExT (10/11)

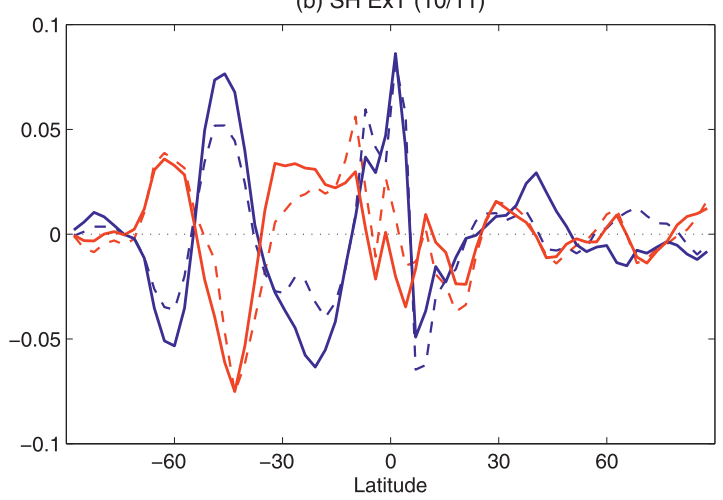

(c) NH ExT (21/13)

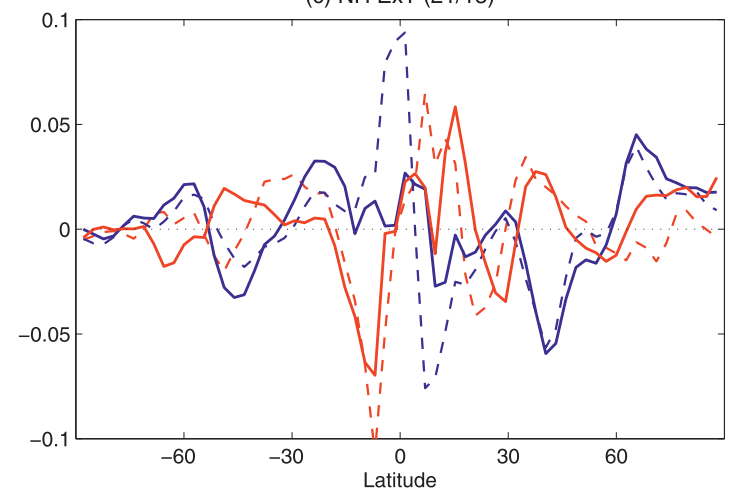

FIG. 8. Zonal-mean $P-E$ trend uncertainty regressed onto EOF1 of $\Psi$ trend uncertainty (solid) and EOF1 of uncertainty in zonalmean $P-E$ trends (dashed) in the (a) tropics, (b) southern extratropics, and (c) northern extratropics $\left(\mathrm{mm} \mathrm{day}^{-1}\right)$, from CCSM3 40-member ensemble; DJF in blue and JJA in red. Percent variance explained by EOF1 of $P-E$ trend uncertainty is given in the top-right corner of each panel, with the first value in DJF and the second in JJA.

tropics for unknown reasons. Thus, the leading patterns of $P-E$ trend uncertainty are largely explained by those of the mean meridional circulation trend uncertainty. In particular, tropical $\Psi$ EOF1 in both seasons (Fig. 8a), characterized by a modulation of HC strength, is accompanied by a meridional shift of the ITCZ. The extratropical $\Psi$ EOF1 in both seasons (Figs. $8 \mathrm{~b}$ and $8 \mathrm{c}$ ), associated with the annular modes, is accompanied by a tripole pattern of $P-E$ : a positive (negative) annular mode is associated with high-latitude moistening (drying), midlatitude drying (moistening), and subtropical moistening (drying), as reported in Kang et al. (2011). This linkage between the trend uncertainties in extratropical $\Psi$ and $P-E$ is stronger in the SH, possibly because the zonal-mean diagnostics are more representative of the SH climate system.

\section{Summary}

By means of an ensemble of 40 integrations of the CCSM3 coupled model forced with the A1B GHG scenario and ozone recovery from 2000 to 2060, we have investigated future trends and associated uncertainties in the tropical mean meridional circulation arising from internal climate variability. We have focused on three simple metrics: the strength, width, and height of the Hadley circulation.

Three features emerge robustly from our large ensemble of model integrations. First, weakening of the HC occurs only in the $\mathrm{NH}$, with $\mathrm{SH}$ trends being largely insignificant. Second, the widening of the HC occurs only in the winter season, irrespective of hemisphere. Third, and perhaps most surprisingly, only a single integration is needed to robustly establish the rising of the tropical tropopause with climate change, and this is irrespective of season.

Also, a careful analysis of the trends in mean meridional stream function reveals a highly complex latitudealtitude structure, dependent on the season and the hemisphere under consideration. This suggests that trends for many common metrics used to analyze the expansion of the tropics are likely very uncertain, and ought to be used with caution. 
We have taken advantage of several 100-yr-long timeslice integrations with the atmospheric model component to determine the relative roles of direct and indirect (via SST changes) radiative effects of changes in atmospheric constituents that are responsible for the modeled trends in HC metrics. We have found that SST changes are largely responsible for the $\mathrm{HC}$ trends, with the direct atmospheric radiative effect playing only a very minor role. Our finding that SST changes are the primary driver of increases in $\mathrm{HC}$ width differs from the results of $\mathrm{Lu}$ et al. (2009), who found that direct atmospheric radiative forcing changes were responsible for HC widening during the period 1950-2000. Differences in the relative amplitudes and patterns of SST changes in the two studies due to different time periods under consideration, as well as differences in the strength of atmospheric radiative forcing, may account for the discrepancy. Note also that SST changes in Lu et al. (2009) are largely internal as opposed to forced by GHG (see Deser and Phillips 2009).

We have also examined the source of the uncertainty in future $\mathrm{HC}$ trends. The leading pattern of uncertainty in the mean meridional circulation trends, as determined from an EOF analysis of the 40 individual ensemble members, was found to be associated with the modulation of the HC strength in the tropics and the annular mode of atmospheric circulation variability in the extratropics, in both seasons and hemispheres. Furthermore, correlations between the leading modes of uncertainty in the CCSM3 and CAM3 ensembles indicate that much of the spread in the future tropical circulation trends owes its existence to ocean-atmosphere coupling. In particular, the correlation coefficient between the leading PC records of uncertainty in the mean meridional circulation trends and the trend of each $\mathrm{HC}$ metric reveals that $\mathrm{HC}$ strength uncertainty is controlled primarily by tropical variability resulting from oceanatmosphere coupling, whereas HC edge uncertainty is associated mostly with extratropical variability internal to the atmosphere. Finally, we have shown that the leading pattern of uncertainty in the trends of the mean meridional circulation is able to explain most of the leading pattern of uncertainty in the trends of the hydrological $(P-E)$ cycle, in the tropics and the extratropics, and in both seasons. A similar strong linkage between projected changes in precipitation and changes in the atmospheric circulation has recently been reported by Scheff and Frierson (2012).

Acknowledgments. We thank Haiyan Teng for her help with data uploading. The work of SMK and LMP was supported, in part, by a grant from the U.S. National Science Foundation to Columbia University. SMK is also supported by the 2013 Creativity \& Innovation Research Fund 1.130033 of UNIST (Ulsan National Institute of Science and Technology). We thank the two anonymous reviewers for their helpful comments and suggestions.

\section{REFERENCES}

Birner, T., 2010: Recent widening of the tropical belt from global tropopause statistics: Sensitivities. J. Geophys. Res., 115, D23109, doi:10.1029/2010JD014664.

Bordoni, S., and T. Schneider, 2010: Regime transitions of steady and time-dependent Hadley circulations: Comparison of axisymmetric and eddy-permitting simulations. J. Atmos. Sci., 67, $1643-1654$.

Branstator, G., and H. Teng, 2010: Two limits of initial-value decadal predictability in a CGCM. J. Climate, 23, 6292-6311.

Davis, S. M., and K. H. Rosenlof, 2012: A multidiagnostic intercomparison of tropical-width time series using reanalyses and satellite observations. J. Climate, 25, 1061-1078.

Deser, C., and A. S. Phillips, 2009: Atmospheric circulation trends, 1950-2000: The relative roles of sea surface temperature forcing and direct atmospheric radiative forcing. J. Climate, 22, 396-413.

, A. Capotondi, R. Saravanan, and A. S. Phillips, 2006: Tropical Pacific and Atlantic climate variability in CCSM3. J. Climate, 19, 2451-2481.

— A. Phillips, V. Bourdette, and H. Teng, 2012: Uncertainty in climate change projections: The role of internal variability. Climate Dyn., 38, 527-546, doi:10.1007/s00382-010-0977-x.

Esler, J., L. Polvani, and R. Plumb, 2000: The effect of the Hadley circulation on the propagation and reflection of planetary waves in a simple one-layer model. J. Atmos. Sci., 57, 1536-1556.

Gastineau, G., H. L. Treut, and L. Li, 2008: Hadley circulation changes under global warming conditions indicated by coupled climate models. Tellus, 60A, 863-884.

Held, I. M., and P. J. Phillips, 1990: A barotropic model of the interaction between the Hadley cell and a Rossby wave. J. Atmos. Sci., 47, 856-869.

_ cycle to global warming. J. Climate, 19, 5686-5699.

Johanson, C. M., and Q. Fu, 2009: Hadley cell widening: Model simulations versus observations. J. Climate, 22, 2713-2725.

Kang, S. M., and L. M. Polvani, 2011: The interannual relationship between the latitude of the eddy-driven jet and the edge of the Hadley cell. J. Climate, 24, 563-568.

— warming: Winter versus summer. J. Climate, 25, 8387-8393.

, L. M. Polvani, J. C. Fyfe, and M. Sigmond, 2011: Impact of polar ozone depletion on subtropical precipitation. Science, 332, 951-954.

Lu, J., G. Vecchi, and T. Reichler, 2007: Expansion of the Hadley cell under global warming. Geophys. Res. Lett., 34, L06805, doi:10.1029/2006GL028443.

, G. Chen, and D. M. W. Frierson, 2008: Response of the zonal mean atmospheric circulation to El Niño versus global warming. J. Climate, 21, 5835-5851.

— C. Deser, and T. Reichler, 2009: Cause of the widening of the tropical belt since 1958. Geophys. Res. Lett., 36, L03803, doi:10.1029/2008GL036076.

Meehl, G. A., and Coauthors, 2006: Climate change projections for the twenty-first century and climate change commitment in the CCSM3. J. Climate, 19, 2597-2616. 
C. Covey, T. Delworth, M. Latif, B. McAvaney, J. F. B. Mitchell, R. J. Stouffer, and K. E. Taylor, 2007: The WCRP CMIP3 multimodel dataset. Bull. Amer. Meteor. Soc., 88, 1383-1394.

Polvani, L. M., M. Previdi, and C. Deser, 2011: Large cancellation, due to ozone recovery, of future Southern Hemisphere atmospheric circulation trends. Geophys. Res. Lett., 38, L04707, doi:10.1029/2011GL046712.

Reichler, T., M. Dameris, and R. Sausen, 2003: Determining the tropopause height from gridded data. Geophys. Res. Lett., 30, 2042, doi:10.1029/2003GL018240.

Santer, B. D., and Coauthors, 2003: Contributions of anthropogenic and natural forcing to recent tropopause height changes. Science, 301, 479-483.

Sausen, R., and B. Santer, 2003: Use of changes in tropopause height to detect human influences on climate. Meteor. Z., 12, 131-136.
Scheff, J., and D. M. W. Frierson, 2012: Robust future precipitation declines in CMIP5 largely reflect the poleward expansion of model subtropical dry zones. Geophys. Res. Lett., 39, L18704, doi:10.1029/2012GL052910.

Schneider, T., and S. Bordoni, 2008: Eddy-mediated regime transitions in the seasonal cycle of a Hadley circulation and implications for monsoon dynamics. J. Atmos. Sci., 65, 915934.

Seidel, D. J., Q. Fu, W. J. Randel, and T. J. Reichler, 2008: Widening of the tropical belt in a changing climate. Nat. Geosci., 1, $21-24$

Thompson, D., and J. Wallace, 2000: Annular modes in the extratropical circulation. Part I: Month-to-month variability. J. Climate, 13, 1000-1036.

Vecchi, G. A., and B. J. Soden, 2007: Global warming and the weakening of the tropical circulation. J. Climate, 20, 43164340. 